\title{
Adsorption and Desorption Studies on Reusing Chitosan as an Efficient Adsorbent
}

\author{
Simona Schwarz ${ }^{1}$, Dana Schwarz ${ }^{1}$, Wolfgang Ohmann², Sebastian Neuber ${ }^{2}$ \\ ${ }^{1}$ Leibniz-Institut für Polymerforschung Dresden e.V. \\ Hohe Str. 6, Dresden, Germany \\ simsch@ipfdd.de; schwarz-dana@ipfdd.de \\ ${ }^{2}$ UVR-FIA GmbH \\ Chemnitzer Straße 40, Freiberg, Germany \\ ohmann@uvr-fia.de; sebastian.neuber@tele2.de
}

\begin{abstract}
This paper describes the adsorption and desorption of copper sulfate ions on chitosan as adsorbent material. The recirculation of the biopolymer chitosan is an important feature for an adsorbent. Chitosan possesses the characteristic to adsorb copper ions as well as sulfate ions simultaneously. The verification is carried out by means of AAS and SEM. The adsorbed copper sulfate ions were removed from chitosan by treatment with sulfuric acid. Therefore, it is possible to reuse chitosan as an adsorbent several times.
\end{abstract}

Keywords: Removal of Cupper And Sulfate Ions, Chitosan, Desorption.

\section{Introduction}

In contrast to some organic contaminants in water, heavy metals are not biodegradable. Many of them are toxic or carcinogenic, such as zinc, lead, chromium, mercury, cadmium, copper, and nickel. They are accumulated and transmitted in living beings. Heavy metals damage human health. Therefore, the pollution of water bodies by heavy metals should not be neglected. This publication deals with the removal of copper and sulfate ions. The maximum permissible concentration of some metals in drinking water for Germany is listed in BGBl1 2001. The limit value for copper and sulfate ions is 2 $\mathrm{mg} / \mathrm{L}$ and $200 \mathrm{mg} / \mathrm{L}$, respectively.

Too much copper leads to arthritis and other inflammations of the respiratory and digestive tract. Increased copper stress leads to high blood pressure, an increased risk of heart attack and disorders of the liver metabolism. In addition, an increased copper level increases the formation of free radicals and can lead to depression and nervous diseases.

In animals, copper intoxication of $300 \mathrm{ppm}$ or more leads to liver cell destruction, which is usually symptom-free and of a regenerative nature. From a copper concentration of 900 ppm upwards, irreversible liver cell damage can occur. Excess copper is excreted via the kidneys and leads to deposits.

An increased concentration of sulfate ions leads to acidification of water bodies and weathering of steel and concrete structures, e. g. bridges.

Adsorption is increasingly used to separate desirable substances or to purify undesirable substances from water. The separation processes by adsorption are at an industrial level. Nevertheless, a suitable adsorbent material needs to feature a high absorption capacity combined with a low economic cost for realizing the adsorption processes at a commercial level. Chitosan, derived from chitin, was investigated as such an adsorber material. In order to minimize the costs of the adsorber material, recycling is desirable.

Chitin (Greek: chitón, "shell") is the second most abundant natural polymer and along with cellulose the most widespread polysaccharide. The main source of chitin is from crab, shrimp and lobster crust. The second main source of chitin are insects (grasshoppers, butterflies, mosquitoes, flies, silkworm dolls shell). Chitosan is technically obtained from chitin by deacetylation. This is done by treatment with hot sodium hydroxide solution or enzymatically. Both processes are used technically. In terms of quantity, the alkaline procedure is clearly in the foreground [6]. 


\section{Experimental}

Chitosan from BioLog GmbH (Germany) was used as flakes with a degree of deacetylation (DA) of $85 \%$.

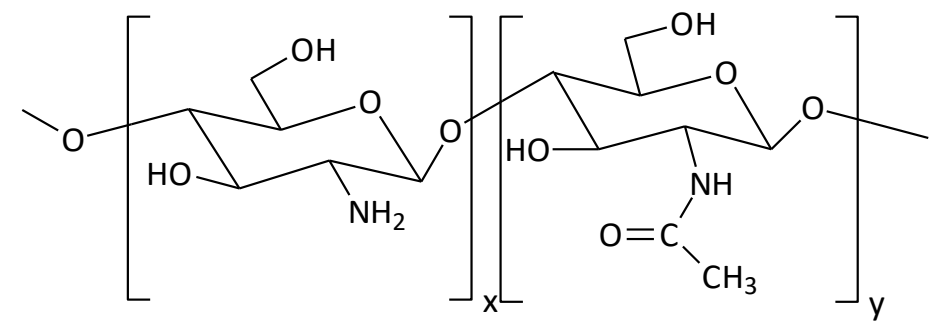

Fig. 1: Structure of chitosan.

For the adsorption measurement an Omnifit-chromatography column with a diameter of $25 \mathrm{~mm}$ (msscientific Chromatographie-Handel $\mathrm{GmbH}$, Berlin) was used. 25 g Chitosan were added to the column and treated with a 5\% solution of copper sulfate. For the desorption, a $10 \%$ sulfuric acid solution was used.

The determination of the metal ion concentrations in solution was carried out with the DR2800 spectrophotometer from HACH-Lange GmbH (Germany). The DR2800 is a microprocessor-controlled spectrophotometer with reference beam technology and a wavelength range of $340-900 \mathrm{~nm}$, which is suitable for routine analysis and own applications (programmable). Related special cuvette tests are recognized by barcode.

Atomic adsorption spectroscopy (AAS) was used for the quantitative and qualitative determination of chemical elements.

In scanning electron microscopy (SEM), an electron beam is bundled by means of a magnetic field and blasted onto the sample. The electric field usually accelerates the electrons with a voltage of 8 to $30 \mathrm{kV}$.

\section{Results}

Chitosan flakes were packed into a column and a copper sulphate solution was pumped through. At certain times, the eluate is examined by means of AAS and spectrophotometry with regard to the ion content. Figure 2 shows the copper ion and sulfate ion content as a function of time. After 35 minutes, the first copper and sulfate ions were detected. Subsequently, the content of both ions increased with time. Copper and sulfate ions were absorbed uniformly. The sorption of anions to chitosan in literature is described in [1-5]. After approx. $2 \mathrm{~h}$ adsorption time a plateau is reached.

The adsorption of crystals on chitosan was detected by SEM images (see Fig. 2). An additional support of the statements that copper and sulfate ions were adsorbed at the same time could be carried out by means of SEM-EDX images, as already described in [3]. Depending on the time, pictures were taken of the column filled with chitosan. The adsorption of copper ions is clearly visible due to the intense blue colouring of the adsorber material chitosan over time, see Fig. 3a. Even after intensive blue colouring of the adsorber material, copper sulphate ions are still adsorbed. In order to be able to use the adsorber material several times, investigations were carried out to remove copper sulfate ions. The adsorbed copper sulfate ions were dissolved with sulphuric acid. Chitosan is insoluble in sulphuric acid. Fig. $3 b$ shows images after different treatment times with sulphuric acid. Copper sulfate ions were completely removed from the adsorber material. 

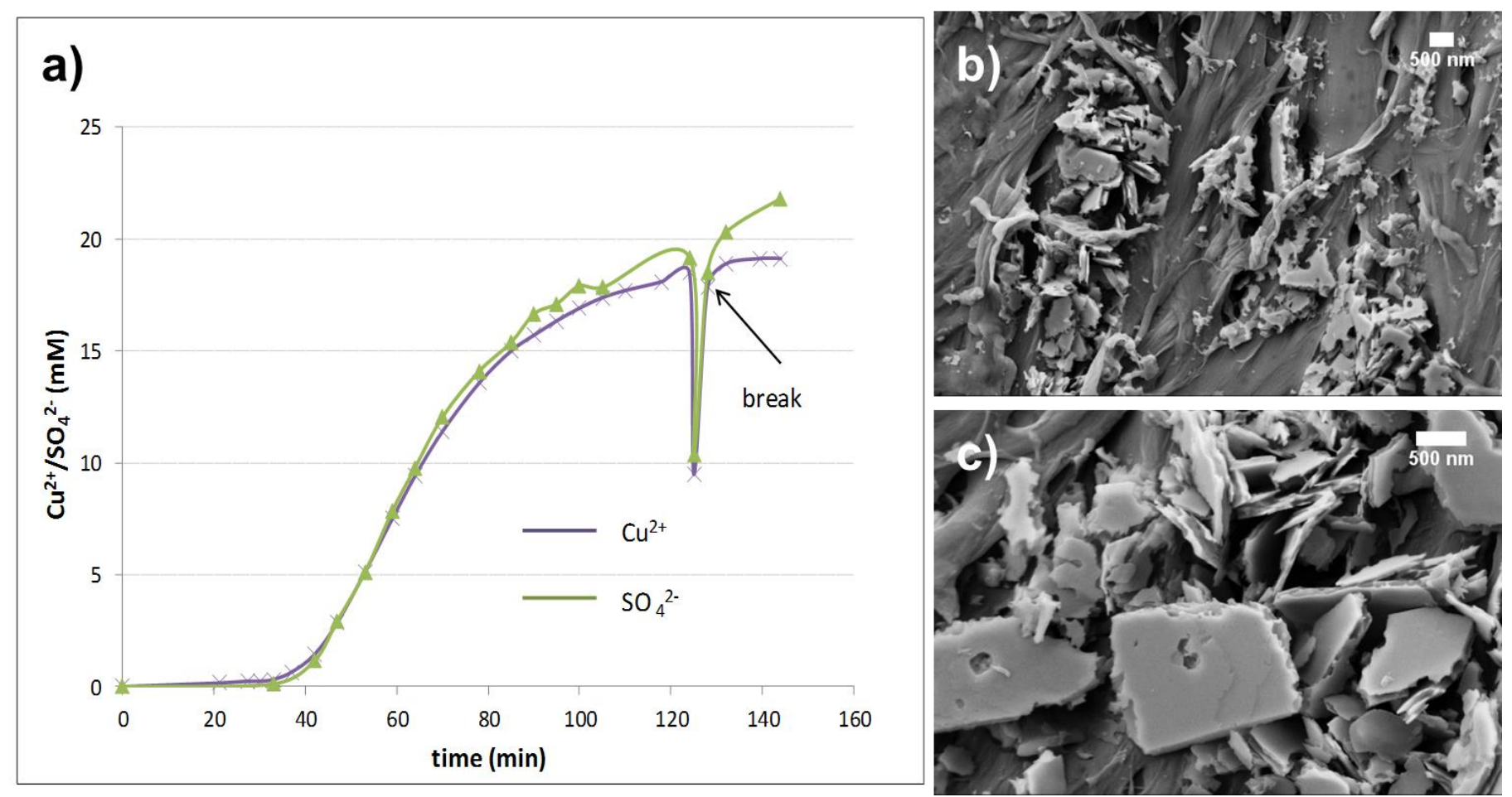

Fig. 2: a) Copper ion and sulfate ion content as a function of time, determined by means of AAS, b) SEM images, after an adsorption time of $30 \mathrm{~min}$, magnification 10000x, c) SEM images, after an adsorption time of 30 min, magnification 20000x.

a)

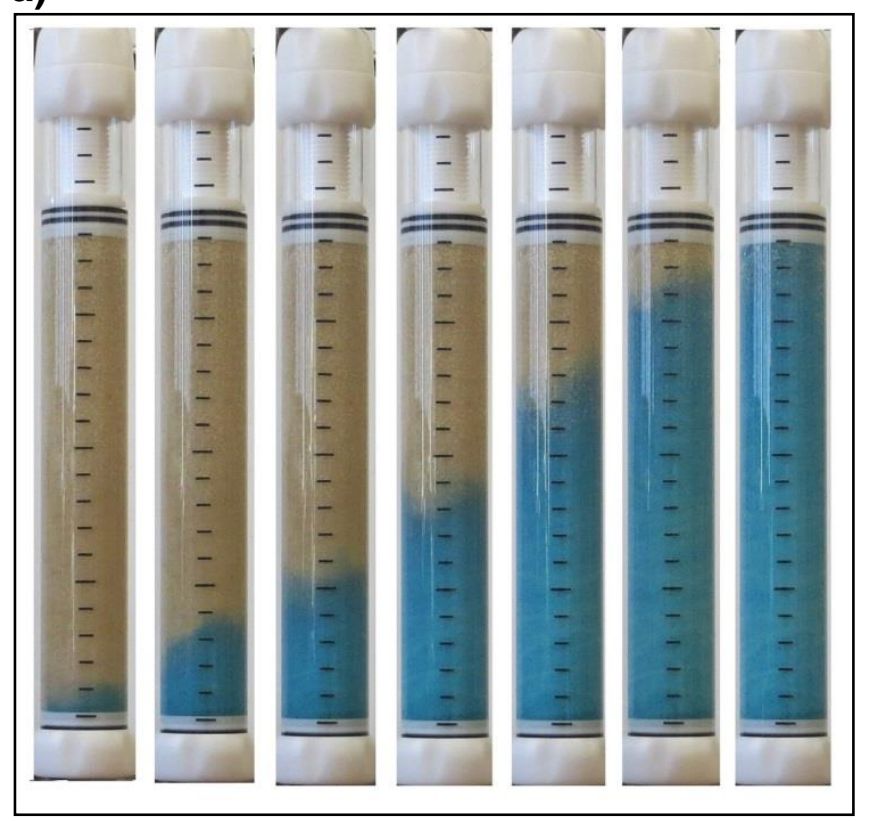

b)

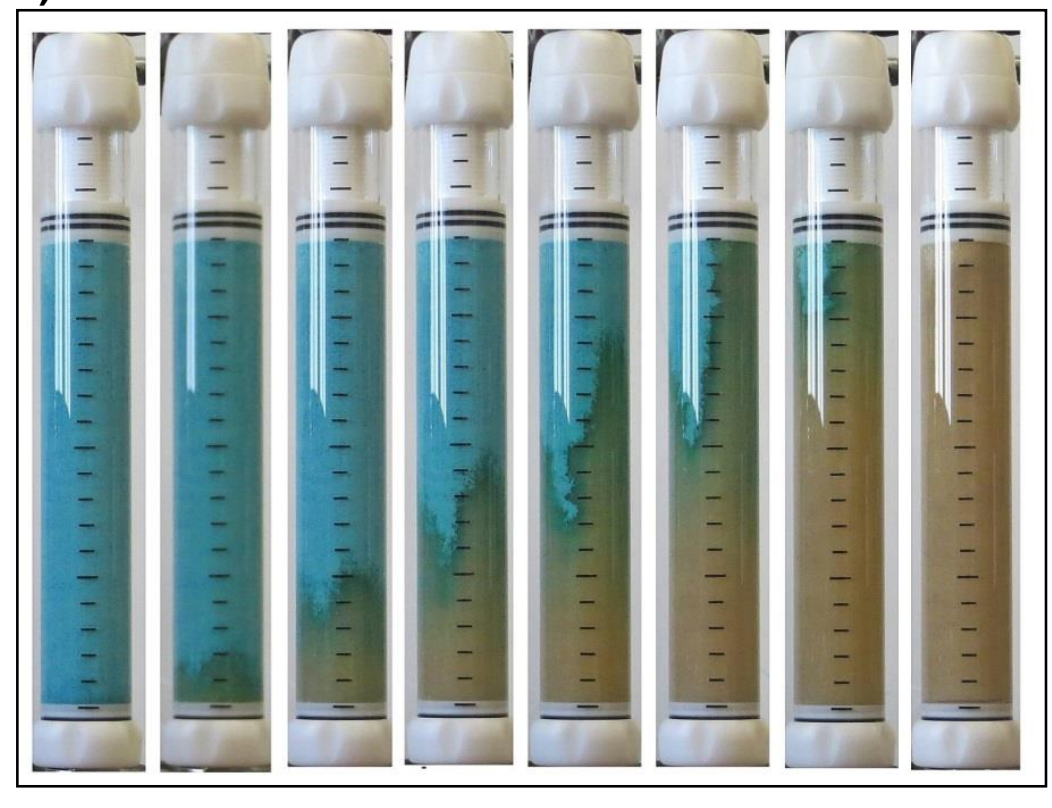

Fig. 3: Images of the adsorption and desorption process in dependence of time of a column filled with chitosan flakes after a) adsorption of copper sulphate ions and $b$ ) desorption of copper sulfate ions by sulfuric acid.

If the material is reused for the separation of copper sulfate ions, the adsorption capacity decreases to about a quarter of the adsorption capacity in the first cycle, see Fig. 5. $4300 \mathrm{mg}$ could be adsorbed in the first use, and only $1000 \mathrm{mg}$ in the second and third use. In further adsorption and desorption steps, we obtained the same result. However, if the adsorber 
material is washed again after desorption and thus subjected to sulfuric acid treatment and rinsed with sodium hydroxide solution, activation takes place. Such activation enables the multiple use of chitosan as an adsorber material without any loss of adsorption.

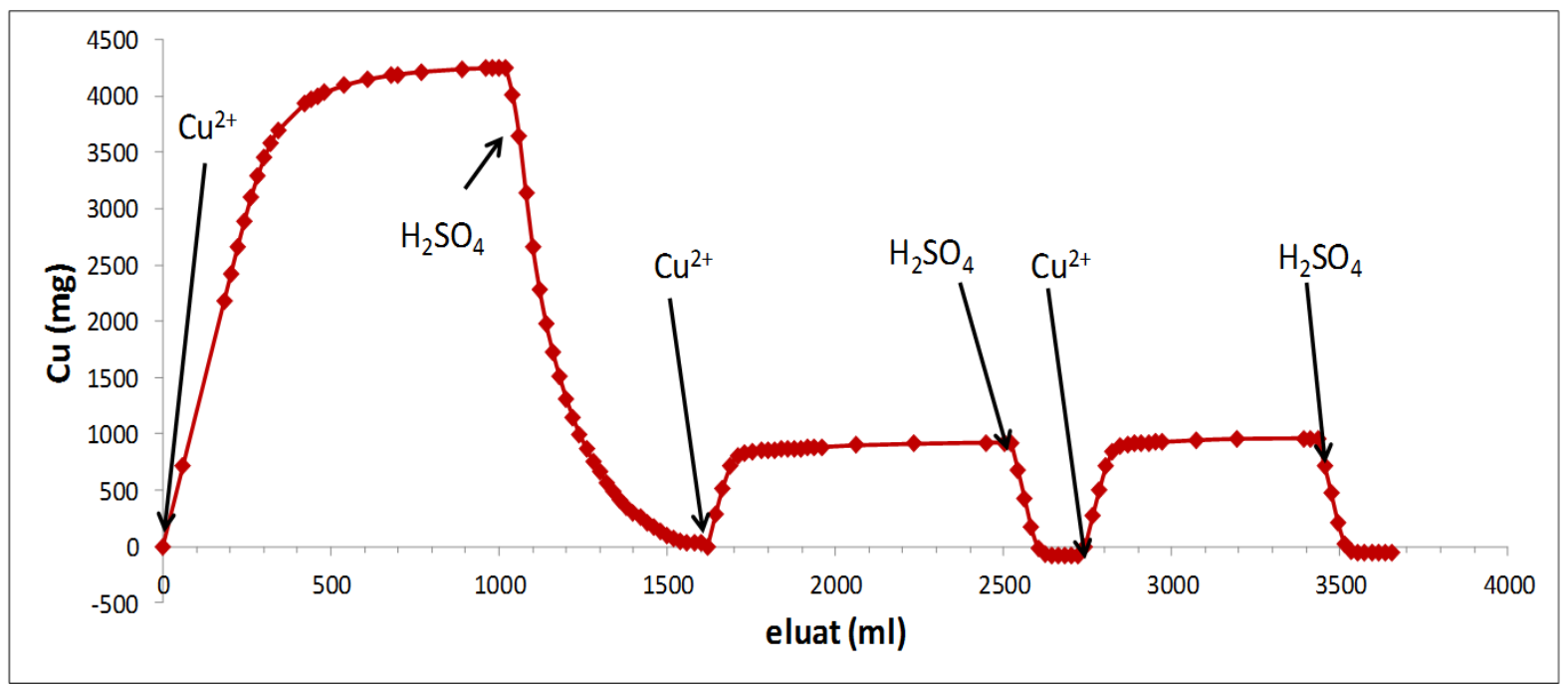

Fig. 5: Multiple loading of the column filled with chitosan with 5\% copper sulfate solution and desorption by sulfuric acid treatment.

\section{Conclusion}

Chitosan is a waste product in food industry and an excellent adsorbent material for copper sulfate ions. The desorption of copper sulfate ions can be achieved by the treatment with sulfuric acid. Although the total amount of copper sulfate ions could be removed, the following adsorption capacities were significantly lower in comparison to the first adsorption process. The continuing sorption process resulted in comparable adsorption capacities. Through multiple usage it becomes a cost effective adsorbent material.

\section{Acknowledgements}

This work was supported by the Central Innovation Programme (ZIM) of the Federal Ministry of Economy and Energy (BMWi) (KF 2022812RH1). The authors thank Biolog Heppe GmbH from Germany for the support of the materials and discussion and cooperativeness."

\section{References}

[1] S. Schwarz, C. Steinbach, K. Wustrack, „Wie das Spreewasser wieder klar werden soll: Chitosan - ein Naturpolymer im Einsatz gegen die Verockerung, " GIT Labor-Fachzeitschrift, p. 3, 2017.

[2] S. Schwarz, M. Mende, D. Schwarz, „Chitosan - A natural adsorbent for copper ions,“ International Journal of Environmental Pollution and Remediation (IJEPR), vol. 4, pp. 15-19, 2016.

[3] M. Mende, D. Schwarz, C. Steinach, S. Schwarz, „Simultaneous adsorption of heavymetal ions and anions from aqueous solutions on chitosan - Investigated by spectrophotometry and SEM-EDX analysis," Colloids and Surfaces A: Physicochemical and Engineering Aspects, vol. 510, pp. 275-282, 2016.

[4] S. Schwarz, C. Steinbach, M. Mende, D. Schwarz, R. Boldt, „Simultane Abstrennung von Eisen- und Sulfationen durch Kristallisation an Chitosanoberflächen," GWF: Wasser, Abwasser, vol. 12, pp. 1135-1143, 2016.

[5] S. Schwarz, C. Steinbach, D. Schwarz, M. Mende, R. Boldt, „Chitosan - The applicatio of a natural polymer against iron hydroxyde deposition," Americal Journal of Analytical Chemistry, vol. 7, pp. 623-632, 2016.

[6] M. Benavente, "Adsorption of Metallic Ions onto Chitosan: Equilibrium and Kinetic Studies," Licentiate Thesis, Royal Institute of Technology Department of Chemical Engineering and Technology, Stockholm, Schweden, 2008. 